\title{
Bond-Slip Models for FPR-Concrete Interfaces Subjected to Moisture Conditions
}

\author{
Justin Shrestha, ${ }^{1}$ Dawei Zhang, ${ }^{2}$ and Tamon Ueda ${ }^{3}$ \\ ${ }^{1}$ Engineering Development Department, Takenaka Civil Engineering \& Construction Co., Ltd., Shinsuna, Koto-ku, \\ Tokyo 136-8570, Japan \\ ${ }^{2}$ Department of Civil Engineering, College of Civil Engineering and Architecture, Zhejiang University, Hangzhou 310058, China \\ ${ }^{3}$ Division of Engineering and Policy for Sustainable Environment, Faculty of Engineering, Hokkaido University, \\ Kita 13 Jo Nishi 8 Chome Kita-ku, Sapporo 060-8628, Japan
}

Correspondence should be addressed to Dawei Zhang; dwzhang@zju.edu.cn

Received 22 September 2016; Accepted 14 December 2016; Published 18 January 2017

Academic Editor: Baolin Wan

Copyright (C) 2017 Justin Shrestha et al. This is an open access article distributed under the Creative Commons Attribution License, which permits unrestricted use, distribution, and reproduction in any medium, provided the original work is properly cited.

\begin{abstract}
Environmental related durability issues have been of great concerns in the structures strengthened with the fiber reinforced polymers (FRPs). In marine environment, moisture is one of the dominant factors that adversely affect the material properties and the bond interfaces. Several short-term and long-term laboratory experimental investigations have been conducted to study such behaviors but, still, there are insufficient constitutive bond models which could incorporate moisture exposure conditions. This paper proposed a very simple approach in determining the nonlinear bond-slip models for the FRP-concrete interface considering the effect of moisture conditions. The proposed models are based on the strain results of the experimental investigation conducted by the authors using 6 different commercial FRP systems exposed to the moisture conditions for the maximum period of 18 months. The exposure effect in the moisture conditions seems to have great dependency on the FRP system. Based on the contrasting differences in the results under moisture conditions, separate bond-slip models have been proposed for the wet-layup FRP and prefabricated FRP systems. As for the verification of the proposed model under moisture conditions, predicted pull-out load was compared with the experimental pull-out load. The results showed good agreement for all the FRP systems under investigation.
\end{abstract}

\section{Introduction}

The use of fiber reinforced polymer (FRP) is extensive in strengthening and rehabilitation of infrastructures. However, there are great concerns regarding the environment-related durability problems. To precisely predict the service life of the strengthened/rehabilitated structures, it is necessary to take account of the environmental durability related deteriorations. In the marine environment, the moisture is considered as one of the dominant factors which could affect both the material and the bond properties of the FRP strengthened/rehabilitated concrete structures. Various existing design guidelines for FRP strengthening reinforced concrete members recommended deterioration coefficient for FRP materials to reflect the effect of exposure environment. The coefficient was usually applied to the material properties of FRP itself, while the effect of environment on the bond-slip relation of FRP-concrete interfaces was not considered. Meanwhile, there are quite a number of studies trying to simulate the marine environmental conditions by altering the materials, immersion solutions, exposure durations, environmental conditions, testing methods, and so forth [1-5]. Among them, most of the studies have pointed out that the moisture conditions severely deteriorated bond interfaces between FRP and substrate concrete while the degree of effect varied. Generally, the moisture affects the interface between FRP and the concrete resulting in the reduction of the bond capacity. Such effects are usually reflected by transition in failure mode from concrete cohesion to the mixed or adhesion failures [1]. The extensive experimental investigation conducted by the authors found that the effect of moisture was largely dependent on the selection of the materials. Among 6 of the commercial FRP systems investigated for the maximum moisture immersion 
period of 18 months, two of the cases suffered significant deterioration in the bond properties compared to the rest of the systems [6]. These experimental findings should be accounted properly into the bond interface properties by incorporating the moisture effects in the bond-slip models.

In order to evaluate the interfacial bond mechanism between FRP and concrete and to simulate the interfacial behavior of FRP strengthened members under moisture condition, there is a necessity to develop related bond stressslip models [7]. Dai et al. [8] proposed a simple analytical method of determining the nonlinear bond stress-slip models, which was proved to predict the bond behavior of the FRP-concrete interface with fairly good accuracy. However, the model was only meant to predict for the cases without the influence of environmental actions that a structure usually experiences during its service life. Some of the available literatures considering such environmental effects in the bond-slip models are briefly summarized hereafter. Dai et al. [9] developed nonlinear bond-slip model for FRP laminates externally bonded to concrete at elevated temperature considering the existing test data of FRP-concrete bonded interfaces at temperatures ranging from 40 to $180^{\circ} \mathrm{C}$. They modified the two-parameter bond-slip model to consider the influences of both temperature induced thermal stress and temperature induced bond degradation. The interfacial fracture energy decreased after approaching the glass transition temperature of the bonding adhesive. The proposed temperature dependent bond-slip model was able to provide reasonably close prediction despite the large scatter of the data. Yun [10] developed an analytical model for bond-slip relationship considering the effect of freeze-thaw cycles. Yun used the measured slip distribution to propose the bondslip relation. According to the model, if the bond length is sufficient then the bond-slip relation for that region does not vary along the bonded area, whereas if the bond length is not sufficient then the bond-slip relation varies with the location.

In a study on effect of moist environment, Ouyang and Wan [11] identified the interface region relative humidity (IRRH) as the primary factor that affected the bond fracture energy of FRP-concrete interface in moist environment and the ultimate bond performance. A deterioration model was developed to describe the local relation between the interfacial fracture energy and the IRRH in moist environment [12]. Similarly, Silva et al. [13] investigated the effect of moisture, salt fog, and temperature cycles on the CFRP/GFRP-toconcrete interfaces for the maximum period of 10,000 hours. The authors compared several components such as maximum bond stresses, ultimate slip, fracture energies, and effective bond length and proposed bond stress-slip laws taking into account those effects.

All the above literatures point out that the bond-slip models incorporating the effects of long-term environmental conditions are extremely scarce and the findings are based on a certain FRP system. But as the environmental durability is greatly dependent on the materials, it is crucial to consider many FRP systems while deriving the interfacial bond models. Therefore, the objective of this paper is to propose interface bond-slip models considering the long-term effect of moisture exposure up to 18 months in 6 commercially

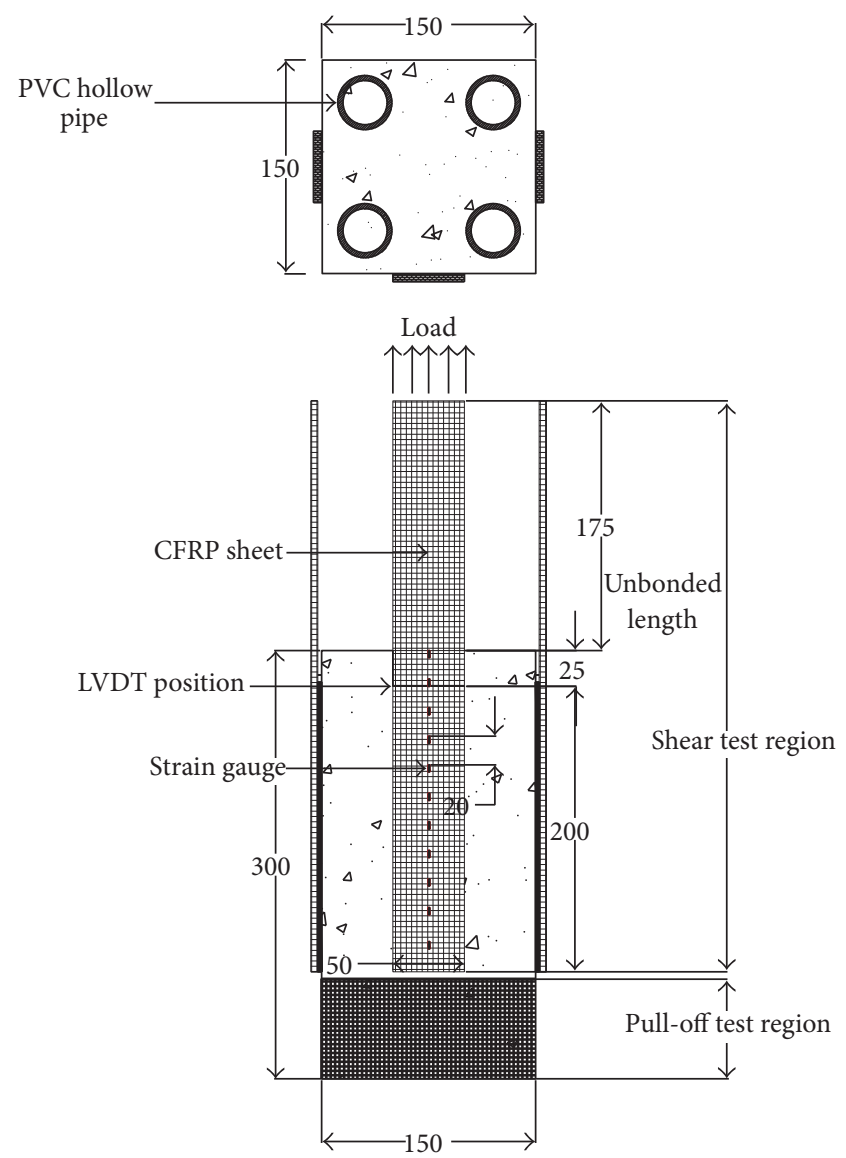

FIGURE 1: Details of bond specimen (unit: $\mathrm{mm}$ ) for single lap shear test.

available FRP systems in the world. Brief experimental information required in the paper is presented hereafter.

\section{Experimental Details}

The experimental program consisted of single lap shear bond specimens prepared by using 6 commercial FPR systems from well-known Japanese, European, and US based manufacturers. This included 4 FRP sheet bonding instances, one plate bonding, and one strand sheet bonding along with the suggested epoxy resins. The 6 systems are identified as SBA, SB-B, SB-C, SB-D, SB-E, and SB-F, respectively. The epoxy resins were two component room curing type resin with base and hardener. The base was a bisphenol-A type epoxy resin, whereas the hardener was modified polyamines. Prior to the bonding of the FRP, primer layer was applied on the concrete for the systems SB-A and SB-B based on the suggestion of the manufacturers.

Altogether 126 concrete prisms were prepared with the dimensions of $150 \times 150 \times 300 \mathrm{~mm}$ as shown in Figure 1 . The compressive strength of the concrete cylinders tested after 28 days of curing was $29.50 \mathrm{MPa}$. For the preparation of the bond specimens, the concrete surface was treated uniformly with a disk grinder till the coarse aggregates were 


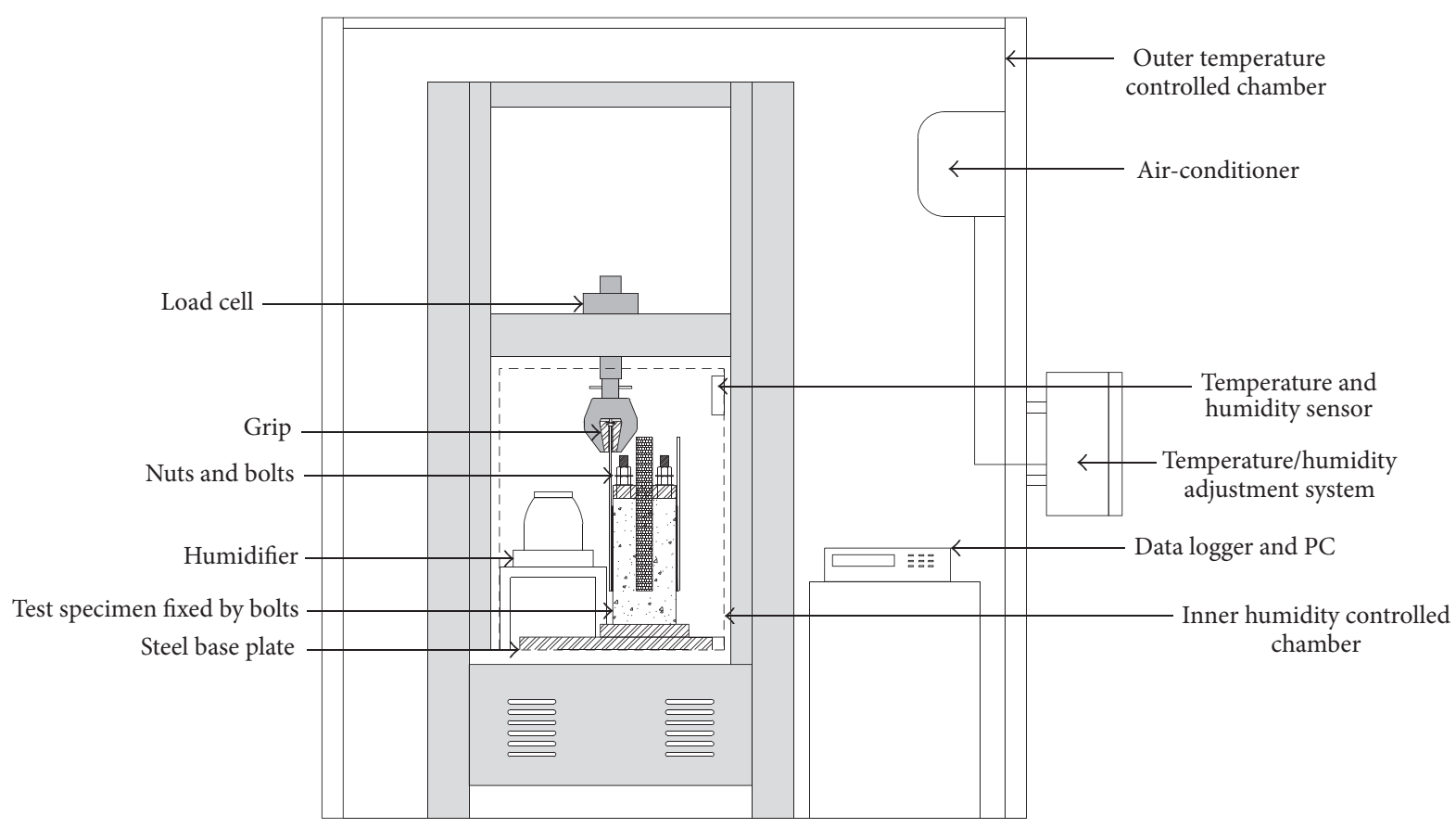

FIGURE 2: Test arrangement schematic for the bond specimen inside the environmental testing chamber.

exposed and cleaned properly. Then FRPs were attached on 3 sides of the concrete following the application procedure of each manufacturer. For the shear bond test, FRP strip of $50 \mathrm{~mm}$ width was attached on the concrete blocks with the bonding length of $200 \mathrm{~mm}$. As for the tensile test, FRP strip of $50 \mathrm{~mm}$ width and $150 \mathrm{~mm}$ length was bonded at the bottom of the specimen to conduct the direct pull-off test. All the specimens were left for curing in the laboratory environmental conditions for more than a month. The nonimmersion specimens, which are also referred to as the 0 -month case, were kept at ambient condition inside the laboratory until the test. As for the moisture exposure conditions, the specimens were completely immersed in a water pool maintained at a constant temperature of $20^{\circ} \mathrm{C}$ for the maximum period up to 18 months. The immersed specimens were taken out from the water every 3-month interval and immediately transferred into the environmental chamber (Figure 2) for the bond tests. Inside the environmental chamber, the humidity of over $85 \%$ and temperature of $20 \pm 3^{\circ} \mathrm{C}$ were maintained throughout the test period. Three samples were tested for each exposure condition to validate the results. However, the strain information was measured only in one of the three cases during the shear bond test at 0-, 6-, 12-, and 18month duration of exposure. The strain gauges were placed at spacing of $20 \mathrm{~mm}$ from the loaded end to $160 \mathrm{~mm}$. The strain gauge arrangements and the moisture chamber are shown in Figure 3.

\section{Experimental Results and Discussions}

The detailed experimental results are reported in Shrestha et al. [14]. Thus, only a brief summary is presented in this paper. According to the results of 18-month exposure, the

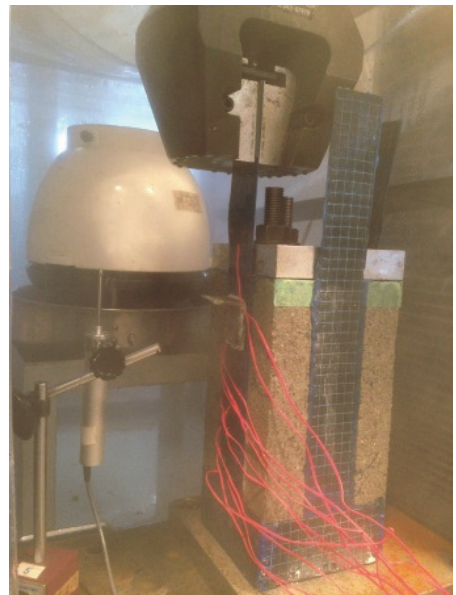

Figure 3: Specimen during the test under moisture condition.

moisture effect varied greatly depending on the FRP systems. Overall, the wet-layup FRP systems performed poorly in comparison with the prefabricated FRP systems after moisture exposure. All the wet-layup FRP systems showed certain deteriorations due to moisture exposure and the effects were quite significant in two of the systems. The average bond strength was reduced by $25 \%$ and $16 \%$, respectively, for SB$\mathrm{C}$ and SB-D after the exposure, whereas the reduction in systems SB-A and SB-B was less than $5 \%$. As indicated by the observation of the failure modes, the reductions were mainly due to local deterioration of the bonds at the interfaces as a result of moisture exposure. Such deterioration of the bond was most serious when the adhesion failures occurred as observed in systems SB-C and SB-D, while transition of 
TABLE 1: Verification of Dai's approach using different FRP bonding systems.

\begin{tabular}{lccccccccc}
\hline Fiber material & System & $A$ & $B$ & $R^{2}$ & $E_{f}\left(\mathrm{~N} / \mathrm{mm}^{2}\right)$ & $t_{f}(\mathrm{~mm})$ & $\left(P_{\text {pre. }}\right)$ & $\left(P_{\text {exp. }}\right)$ & $P_{\text {pre. }} / P_{\text {exp. }}$ \\
\hline CFS & SB-A-0 & 0.0077 & 10.96 & 0.948 & 230000 & 0.111 & 9.78 & 11.57 & 0.84 \\
CFS & SB-B-0 & 0.0065 & 14.46 & 0.954 & 230000 & 0.111 & 8.33 & 9.82 & 0.85 \\
CFS & SB-C-0 & 0.007 & 10.73 & 0.967 & 230000 & 0.218 & 17.52 & 15.81 \\
CFS & SB-D-0 & 0.006 & 11.81 & 0.952 & 240000 & 0.176 & 12.65 & 11.77 \\
CFSS & SB-E-0 & 0.0034 & 14.4 & 0.968 & 245000 & 0.333 & 13.71 & 12.49 & 1.07 \\
CFRP & SB-F-0 & 0.002 & 17.44 & 0.969 & 210000 & 1.4 & 29.55 & 26.06 \\
\hline \multicolumn{2}{l}{ Average of the ratio of the predicted to experimental ultimate load } \\
\hline
\end{tabular}

failure modes from concrete cohesion to the mixed mode resulted in a mere reduction in the bond strength. In contrast, prefabricated FRP systems SB-E and SB-F showed either no effect or some positive effect of moisture exposure conditions. No correlation was found with the evolution of the material properties to explain such phenomenon. However, it is wellknown that the prefabricated FRPs have better and consistent quality than the wet-layup FRPs which is due to the process of resin impregnation and curing of the fibers in the factory. It could be one of the reasons for the overall better performance. But the obvious distinction in the behavior was mainly observed in the failure modes after the moisture exposure. For the wet-layup, it was either mixed or interface failure for most of the cases. In contrast, failure modes for the prefabricated cases were mostly concrete or mixed failure suggesting stronger adhesion bonds at the interface [14].

Finally, the FRP strain results obtained from the experiments were used to develop the bond-slip relations for moisture exposure conditions which is discussed hereafter.

\section{Analytical Approach}

4.1. Review of Dai's Methodology. Dai et al. [8] developed a simple method to determine the local bond stress-slip relationships of FRP sheet-concrete interfaces which required pull-out force and loaded end slip. Based on the method, a simple interfacial shear stress-slip $(\tau-s)$ relationship was proposed with only two parameters; interfacial fracture energy, $G_{f}$, and interfacial material constant $B$. The applicability of the method has already been verified with the experimental results. Brief background of the model is presented hereafter.

Dai et al. [8] used a simple mathematical function as given in (1) which was proved to represent the strain-slip $(\varepsilon-s)$ relationship with a good accuracy when compared with the experimental results.

$$
\varepsilon=f(s)=A\left(1-e^{(-B s)}\right),
$$

where $A$ and $B$ are experimental parameters obtained from the nonlinear regression between the plots of strain-slip relationship. The physical meaning of $A$ corresponds to the maximum strain in the FRP provided the bond length is sufficient and $B$ can be regarded as the ductility index which controls the shape of the bond-slip curve [9].

Then the expression for the $\tau$-s is given by

$$
\tau=A^{2} B E_{f} t_{f} e^{(-B s)}\left(1-e^{(-B s)}\right) .
$$

$E_{f}$ and $t_{f}$ are Young's modulus in MPa and thickness of FRP in $\mathrm{mm}$, respectively.

By integrating $\tau$-s function, the interfacial fracture energy $G_{f}$ can be obtained as

$$
G_{f}=\frac{1}{2} A^{2} E_{f} t_{f}
$$

The final expression of $\tau$-s in terms of $G_{f}$ and $B$ is as follows:

$$
\tau=2 B G_{f}\left(e^{(-B s)}-e^{(-2 B s)}\right) .
$$

The relationship for the ultimate pull-out load is given by

$$
P_{\max }=b_{f} \sqrt{2 E_{f} t_{f} G_{f}} \text {. }
$$

Even though the above approach is not dependent on the FRP reinforcement type, the validity of the above approach has not been tested for the strand sheet and plate bonding cases. Therefore, applicability of Dai's methodology was first confirmed in case of all the six CFRP systems in ambient conditions. As for the evaluation of the accuracy of the model, integral absolute error (IAE) was calculated as given by (6). This IAE factor which is the cumulative error value is sensitive to the deviation of test results in the model. Previous researchers have used this factor to evaluate the accuracy of the model $[15,16]$.

$$
\mathrm{IAE}=\sum \frac{\sqrt{(\text { Expe. }- \text { Theo. })^{2}}}{\sum \mid \text { Expe. } \mid}
$$

Table 1 shows fairly good ratio of predicted ultimate load and experimental ultimate load with the average ratio of close to 1 with an IAE of $11.55 \%$. The predicted ultimate loads were calculated using (5) where the parameter $A$ was determined by regression analysis of the experimental strainslip relationship given by (3) for each individual case.

It is known that Dai's methodology was only developed and confirmed for the ambient environment conditions; however, the applicability of the method in the case of other environmental exposures is still unknown. Therefore, the experimental data obtained from the shear test conducted at different moisture conditions were used to predict the ultimate load to check its applicability other than ambient condition. Figure 4 shows the comparison of predicted and experimental ultimate loads, the former of which were 


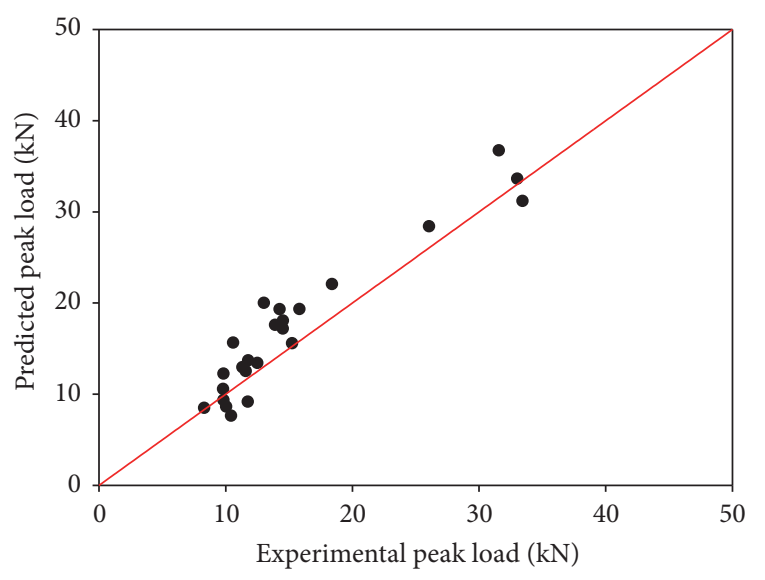

FIGURE 4: Comparison of predicted and experimental ultimate loads using Dai's method. Average ratio of predicted to experimental ultimate load $=1.12$.

calculated by (5) with the regressed value of $A$ for the case at ambient condition. The figure shows slight overestimation of the ultimate load by the predicted model, signifying that the moisture affected cases cannot be predicted precisely with it. The average ratio of predicted to the experimental ultimate load is 1.12 with IAE of $16.43 \%$, which is higher than that for the case without the environmental effects (as shown in Table 1). This could be possibly due to the fact that the strain-slip $(\varepsilon-s)$ relationship in case of the ambient exposure is different from that of the moisture exposure. The local deteriorations caused by the moisture at the interfacial region affects the debonding process. Therefore, to incorporate such local effects in the model, Dai's methodology of determining the bond-slip relation should be modified accordingly.

4.2. Analytical Approach to Nonlinear Bond Stress-Slip Model for Moisture Exposure. The brief steps to determine the bondslip relationships in moisture condition are shown in Figure 5. According to Dai et al.s [8] concept, when there is a sufficient bond length, the pull-out forces and the slips at the loaded end can be measured accurately through which the relationship between the strain in the FRP sheets and the slips can be determined easily. Based on that, a single $\varepsilon$ - $s$ at the loaded end of the FRP was used to determine the values of $A$ and $B$ by nonlinear regression analysis as shown in (1). However, in this study, the local responses along the bond length were measured by strain gauges attached at the regular interval. The corresponding slips at those locations were calculated by integration of strain. The obtained $\mathcal{\varepsilon}-\mathcal{s}$ relationships at such different locations were regressed using a common mathematical function as given in (1), to determine a single regressed curve that would represent the average response of $\mathcal{\varepsilon}-\mathcal{s}$ distribution throughout the bonded length. For the regression purpose, only those locations were selected in which the bond lengths were greater than the effective bond length estimated from the strain distribution. In Figure 6, typical measured strain-slip data at $0,6,12$, and 18 months and their corresponding regressed curve fittings are shown for SBB system. Similarly, the regressed $\varepsilon$ - $s$ curves were determined in all the 6 FRP systems at different exposure durations which are shown in Figure 7. The regression coefficients in all the cases with their correlation factors are given in Table 2 . The values of correlation factor lie within the range of 0.92 to 0.97 , showing a very good agreement between the proposed shape function (see (1)) and the experimental data. For all the FRP systems shown in Figure $7, \varepsilon$-s curves show distinct responses to the moisture exposure durations. The moisture at the interface region seems to influence the load transfer mechanism between FRP composite and concrete, affecting the ultimate strains on the FRPs. Specimens SB-C and SB$\mathrm{D}$ show the greatest reduction in the peak strain values and increase in interfacial slip after exposure, whereas specimens SB-E and SB-F show increase in peak strain after exposure. Such effect is unclear in SB-A case, but SB-B case shows a small reduction in the peak strain after exposure.

Using the obtained regression coefficient values of $A$ for each individual FRP systems at each exposure duration, the fracture energies were calculated using (3). As for the stiffness of the FRP composites, it is assumed to be unaffected by the moisture conditions; thus, the same values provided by the manufacturers were used for the calculations. This assumption seems to be fair in case of CFRP composites, as the carbon fibers are the major component in the composite, which are highly durable material against environmental degradations. However, it cannot be denied that some degradations could occur in epoxy resin binding those fibers or resin-fiber interfaces, but its overall contribution towards the ultimate strength and stiffness would be small for the CFRPs. Both Nguyen et al. [17] and Sciolti et al. [18] have found similar negligible effect of immersion in water on the tensile modulus of the CFRP, when exposed for 1 year and 30 weeks, respectively.

All the calculated fracture energies and the regressed values $A$ and $B$ are presented in Table 2. For the comparison purpose, the table also shows the normalized fracture energy values, which were calculated by (3). For each system, it is the ratio between the fracture energy for a particular exposure duration to the fracture energy for the nonimmersion case (0 months). For systems SB-A, SB-B, SB-C, and SB-D, the normalized fracture energies are mostly less than 1 after exposure indicating the reduction in the bond capacity in presence of moisture. In contrast, SB-E and SB-F show higher fracture energies after exposure indicating improved bond properties after moisture exposure. As the fracture energy and the bond strength are closely correlated (also shown by (5)), their behaviors towards the moisture exposure duration have similar trends in all the FRP systems. The loss/gain in the bond strengths after immersion can be explained by reduction/increment in fracture energy due to degradation/improvement in the bond properties from moisture exposure. Even though many of the previous studies have observed more severe degradation in bond properties with the increase in exposure duration, it was not the case in the present study. Two different sets of responses were obtained based on the FRP systems. Thus, all the systems cannot be generalized into a single common framework. Nevertheless, to visualize the effect of exposure, the immersion cases were simply grouped as one by taking the average of all the values, 


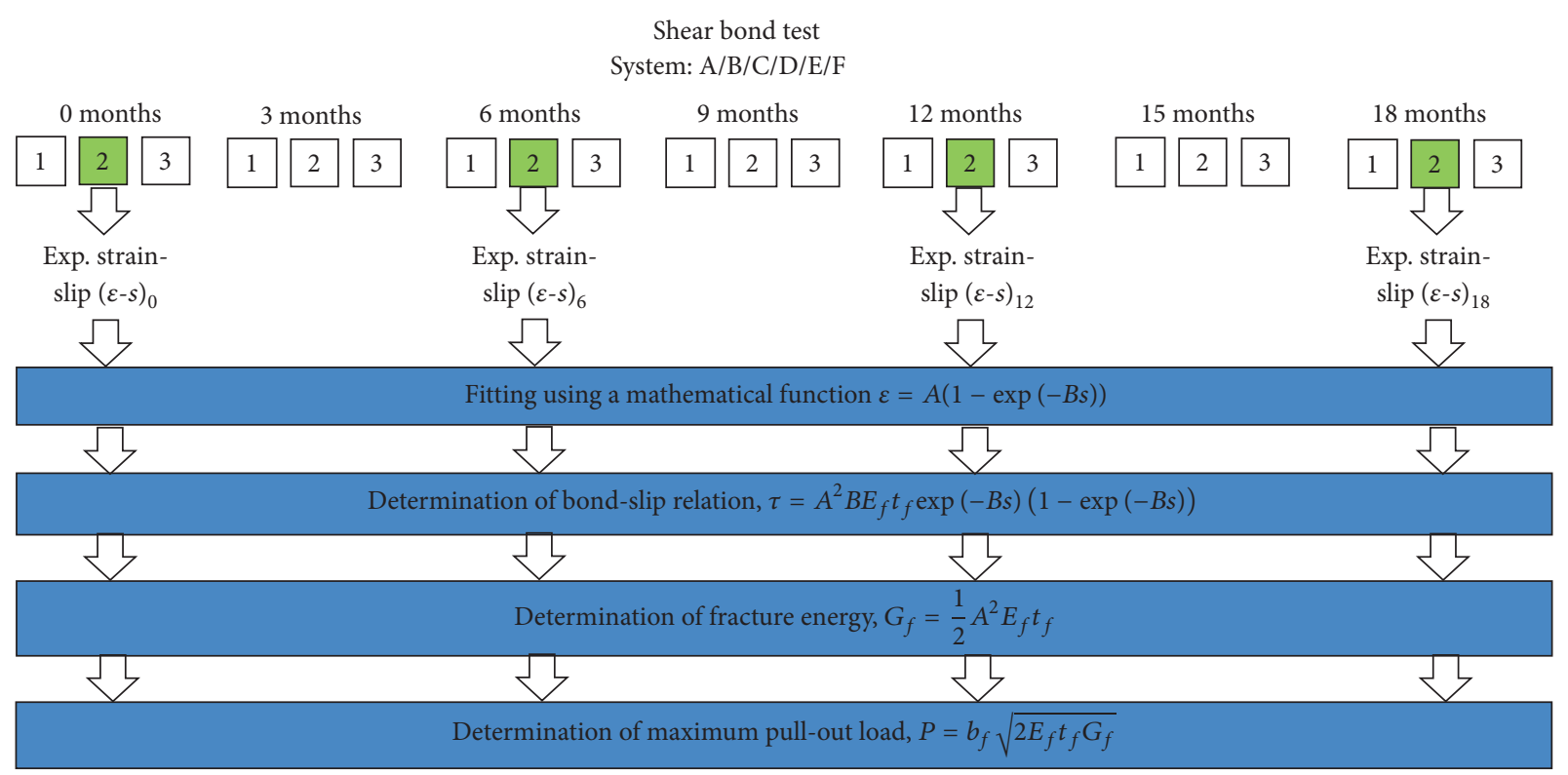

Figure 5: Brief procedure to determine bond-slip relations in moisture conditions.

TABLE 2: Regression coefficients and fracture energies of all the specimens.

\begin{tabular}{|c|c|c|c|c|c|c|c|c|}
\hline Specimens & Exposure duration (months) & $E_{f}\left(\mathrm{~N} / \mathrm{mm}^{2}\right)$ & $t_{f}(\mathrm{~mm})$ & $A$ & $B$ & $R^{2}$ & $G_{f}(\mathrm{~N} / \mathrm{mm})$ & Normalized $G_{f}$ \\
\hline SB-A-0 & 0 & 230000 & 0.111 & 0.00766 & 10.96 & 0.95 & 0.749 & 1.00 \\
\hline SB-A-6 & 6 & 230000 & 0.111 & 0.01066 & 6.08 & 0.93 & 1.451 & 1.94 \\
\hline SB-A-12 & 12 & 230000 & 0.111 & 0.00693 & 12.62 & 0.95 & 0.614 & 0.82 \\
\hline SB-A-18 & 18 & 230000 & 0.111 & 0.00733 & 9.79 & 0.97 & 0.686 & 0.92 \\
\hline SB-B-0 & 0 & 230000 & 0.111 & 0.00652 & 14.46 & 0.95 & 0.543 & 1.00 \\
\hline SB-B-6 & 6 & 230000 & 0.111 & 0.00622 & 13.02 & 0.97 & 0.494 & 0.91 \\
\hline SB-B-12 & 12 & 230000 & 0.111 & 0.00621 & 11.74 & 0.94 & 0.493 & 0.91 \\
\hline SB-B-18 & 18 & 230000 & 0.111 & 0.00591 & 12.06 & 0.96 & 0.446 & 0.82 \\
\hline SB-C-0 & 0 & 230000 & 0.218 & 0.00699 & 10.73 & 0.97 & 1.225 & 1.00 \\
\hline SB-C-6 & 6 & 230000 & 0.218 & 0.00616 & 10.88 & 0.93 & 0.952 & 0.78 \\
\hline SB-C-12 & 12 & 230000 & 0.218 & 0.00561 & 12.12 & 0.95 & 0.790 & 0.64 \\
\hline SB-C-18 & 18 & 230000 & 0.218 & 0.00664 & 10.19 & 0.95 & 1.106 & 0.90 \\
\hline SB-D-0 & 0 & 240000 & 0.176 & 0.00599 & 11.81 & 0.95 & 0.758 & 1.00 \\
\hline SB-D-6 & 6 & 240000 & 0.176 & 0.00549 & 13.93 & 0.92 & 0.637 & 0.84 \\
\hline SB-D-12 & 12 & 240000 & 0.176 & 0.00451 & 16.81 & 0.96 & 0.430 & 0.57 \\
\hline SB-D-18 & 18 & 240000 & 0.176 & 0.00542 & 14.99 & 0.97 & 0.621 & 0.82 \\
\hline SB-E-0 & 0 & 245000 & 0.333 & 0.00336 & 14.40 & 0.97 & 0.461 & 1.00 \\
\hline SB-E-6 & 6 & 245000 & 0.333 & 0.00399 & 13.72 & 0.92 & 0.650 & 1.41 \\
\hline SB-E-12 & 12 & 245000 & 0.333 & 0.00389 & 10.98 & 0.93 & 0.618 & 1.34 \\
\hline SB-E-18 & 18 & 245000 & 0.333 & 0.00432 & 13.99 & 0.95 & 0.762 & 1.65 \\
\hline SB-F-0 & 0 & 210000 & 1.4 & 0.00201 & 17.44 & 0.97 & 0.594 & 1.00 \\
\hline SB-F-6 & 6 & 210000 & 1.4 & 0.00238 & 15.72 & 0.96 & 0.833 & 1.40 \\
\hline SB-F-12 & 12 & 210000 & 1.4 & 0.00240 & 13.36 & 0.96 & 0.847 & 1.43 \\
\hline SB-F-18 & 18 & 210000 & 1.4 & 0.00241 & 15.50 & 0.95 & 0.854 & 1.44 \\
\hline
\end{tabular}

irrespective of the exposure duration, and then compared with the reference or nonimmersion condition. Figure 8 shows such relative changes in both bond strengths and fracture energies. From the figure, significant reductions are evident in SB-C and SB-D cases, with small changes in SB-A and SB-B cases. Nevertheless, such losses in bond strengths and fracture energies could be attributed to degradation of the interfaces caused by moisture conditions. In contrast to such behaviors, specimens SB-E and SB-F showed significant gain in performance after exposure. 


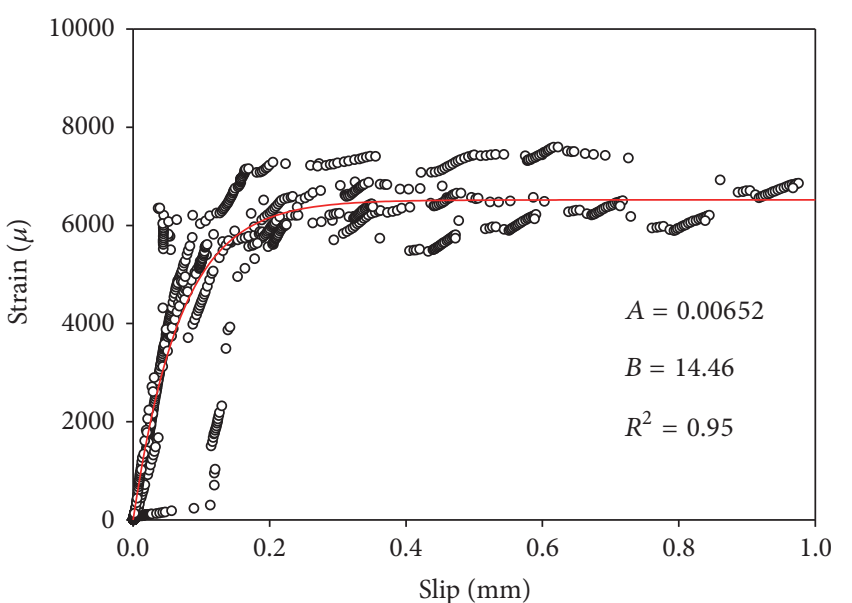

- SB-B-0 exp.

- SB-B-0 reg.

(a)

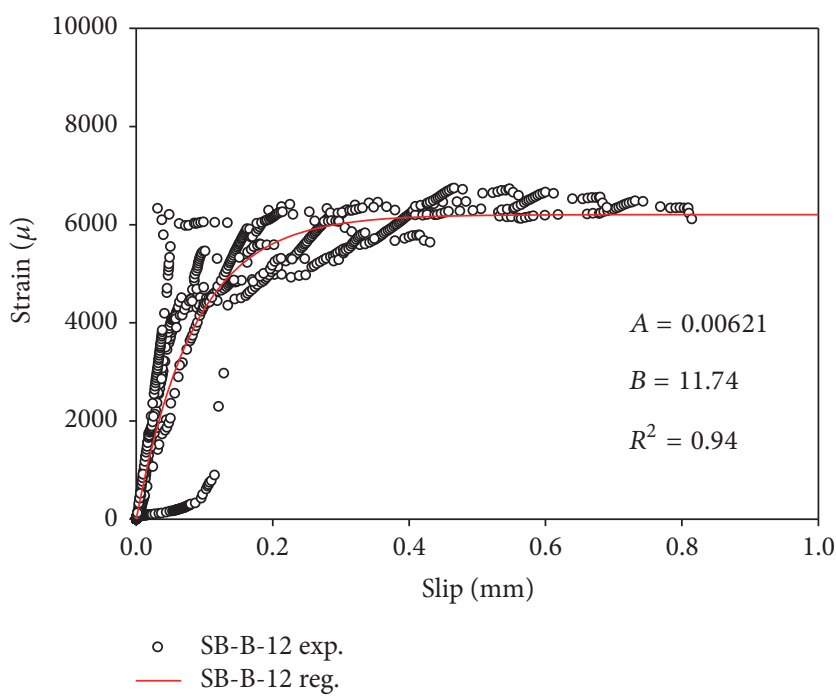

(c)

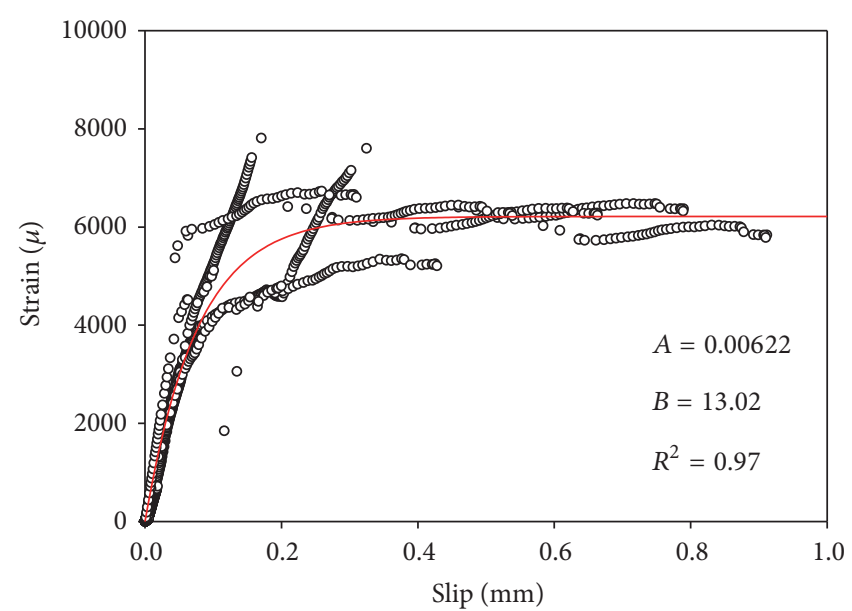

- SB-B-6 exp.

- SB-B-6 reg.

(b)

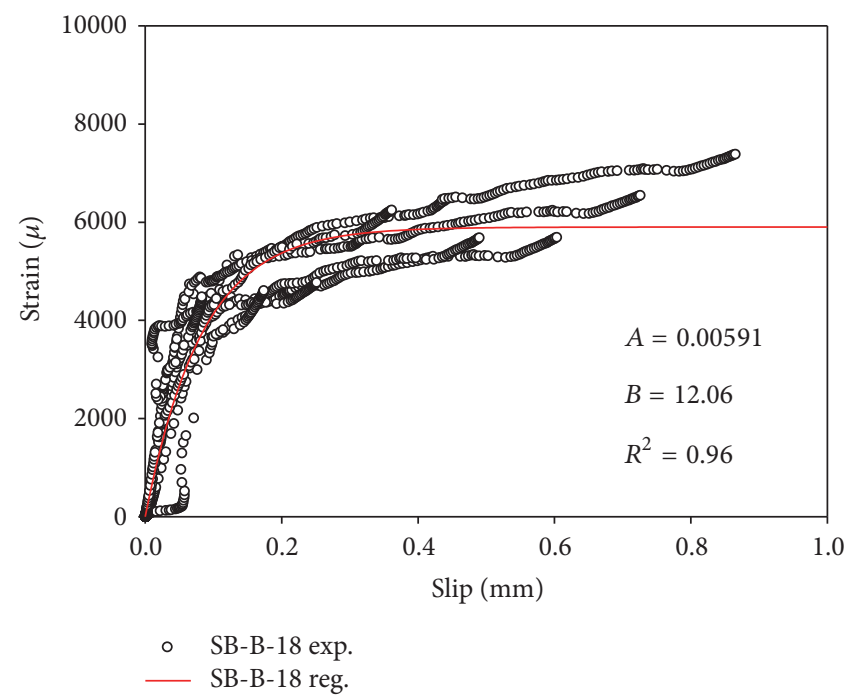

(d)

FIGURE 6: Regressed $\varepsilon$-s curve from the experimental results for specimen SB-B.

The proposed bond-slip models from (4) using two known parameters, $A$ and $B$, were compared with the experimentally obtained local bond-slip curves at different locations as shown in Figure 9. As for the nature of the experimental local bond-slip relationship, there are some variations on the bond-slip curves at different locations even for the same specimen. This means that one cannot choose any one local bond-slip relationship as the representative one. Thus, it is common to take the average response of such local phenomenon. In this regard, the predicted models showed fair agreement showing average response of the experimental data.

4.2.1. Influence of Moisture Exposure on the Parameters $G_{f}$ and $B$. The interfacial fracture energy $\left(G_{f}\right)$, which was calculated from $A$ based on (3), and the ductility index $(B)$ are two of the key parameters in the bond-slip models. While introducing the moisture effect, it is necessary to know the influence of the moisture exposure on those two parameters. The changes in the material or the interfacial properties due to the moisture exposure will be reflected by changes in these parameters. Since each FRP system has its own set of $G_{f}$ and $B$, which are dependent on the FRP material properties, concrete properties, surface roughness, and so forth, they are normalized by the reference/nonimmersion cases, to know the influence of moisture exposure conditions and to make a comparison among different FRP systems. Based on the trend of the experimental results, FRP systems were divided into two categories. The first category includes all the wetlayup FRP systems SB-A, SB-B, SB-C, and SB-D that showed some form of reductions in the bond strength and the fracture energy after the exposure to moisture, whereas the second category consisted of prefabricated FRP systems SB-E and 

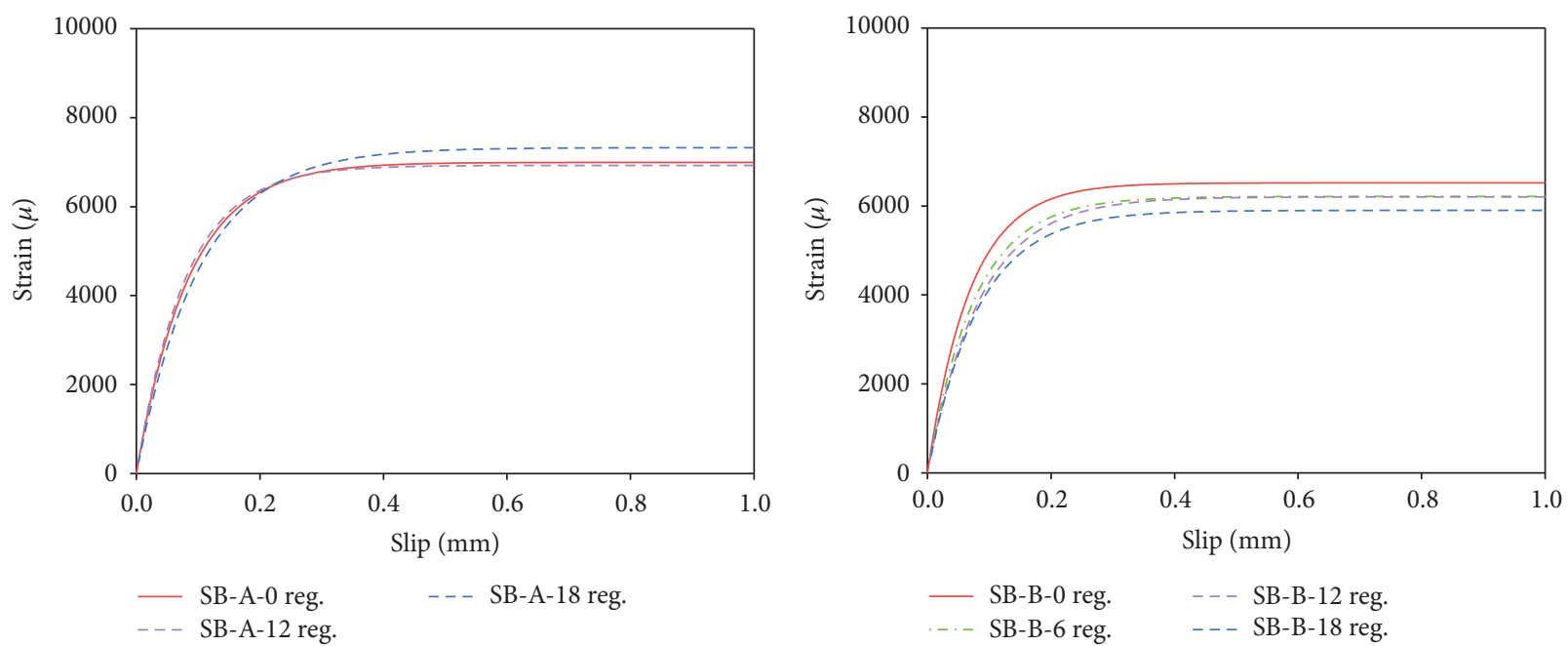

(a)
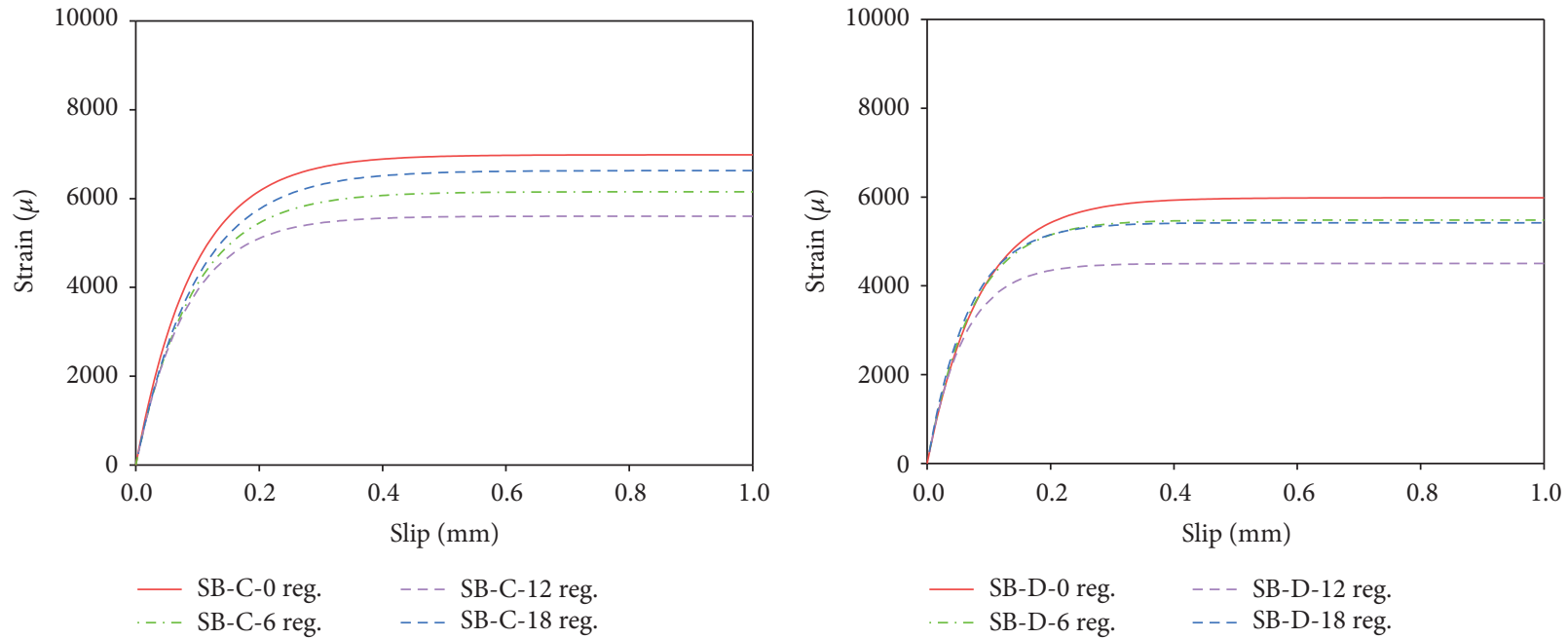

(c)
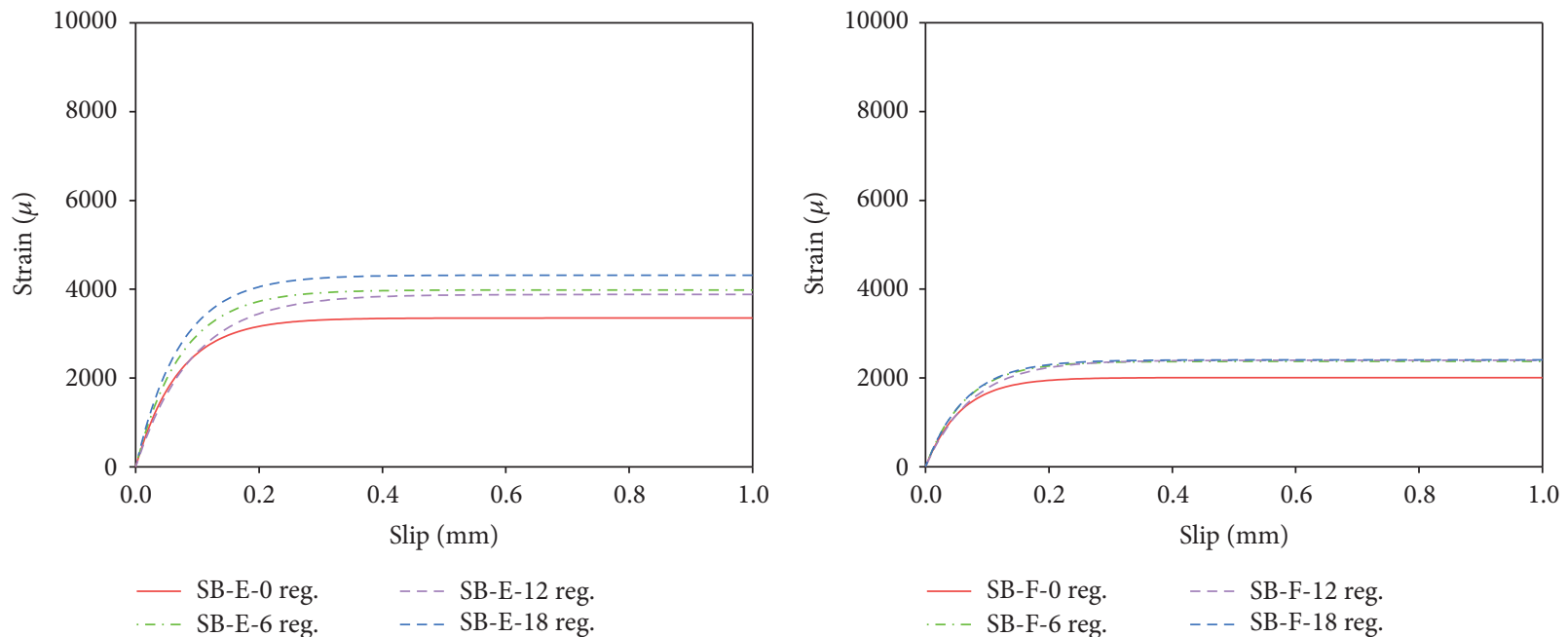

(e)

(f)

Figure 7: Regressed $\varepsilon$-s curves for all the specimens. 


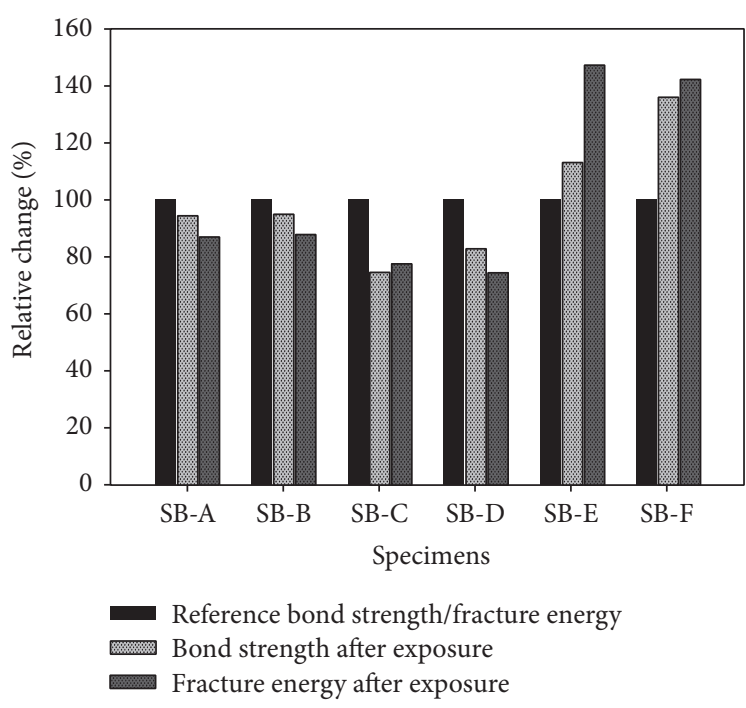

FIGURE 8: Relative change in bond strength and fracture energy after immersion.

SB-F that showed improvement in the bond strength and the fracture energy after the exposure to moisture.

To evaluate such effect of moisture, the parameters $B$ and $G_{f}$ at any exposure duration ( $t$, in months) was normalized by the nonimmersion case ( 0 months). $B_{t}^{\text {Env. }}$ and $G_{f_{t}}^{\text {Env. }}$ are the ductility parameter and the interfacial fracture energy, respectively, for immersion case, whereas $B_{0}$ and $G_{f_{0}}$ are for the nonimmersion case. The effect of moisture exposure duration on the normalized parameters $B_{t}^{\text {Env. }} / B_{0}$ for the wet-layup FRP systems and the prefabricated FRP systems were fitted into an exponential relation which are shown in Figures 10(a) and 10(b), respectively. Similarly, the effect of moisture exposure duration ( $t$, in months) on the normalized parameters $G_{f_{t}}^{\text {Env. }} / G_{f_{0}}$ for the wet-layup FRP systems and the prefabricated FRP systems were also best fitted in an exponential relation which are shown in Figures 11(a) and 11(b), respectively. Those figures clearly indicate larger effect of exposure durations until the first 6 months and then remained almost unchanged until the 18 months. The following expressions were obtained from a simple regression analysis which best described the nature of the parameters' dependency on the exposure duration.

In case of the wet-layup FRP systems,

$$
\begin{aligned}
\left(B_{t}^{\text {Env. }}\right)_{w} & =B_{0}\left(1.05-0.05 e^{-0.40 t}\right) \\
\left(G_{f_{t}}^{\text {Env. }}\right)_{w} & =G_{f_{0}}\left(0.8+0.2 e^{(-0.38 t)}\right) .
\end{aligned}
$$

In case of the prefabricated FRP systems,

$$
\begin{aligned}
\left(B_{t}^{\text {Env. }}\right)_{p} & =B_{0}\left(0.85+0.15 e^{-0.25 t}\right) \\
\left(G_{f_{t}}^{\text {Env. }}\right)_{p} & =G_{f_{0}}\left(1+0.45\left(1-e^{(-0.20 t)}\right)\right) .
\end{aligned}
$$

Based on the above expressions from (7)-(10), the effect of moisture conditions is incorporated in the parameters $B_{t}^{\mathrm{Env}}$.
TABLE 3: Calculated values for $B_{t}^{\text {Env. }}$ and $G_{f_{t}}^{\text {Env. }}$.

(a)

\begin{tabular}{lccc}
\hline Specimen & Exposure duration (months) & $\left(B_{t}^{\text {Env. }}\right)_{w}$ & $\left(G_{f_{t}}^{\text {Env. }}\right)_{w}$ \\
\hline SB-A-0 & 0 & 10.96 & 0.75 \\
SB-A-3 & 3 & 11.34 & 0.65 \\
SB-A-6 & 6 & 11.46 & 0.61 \\
SB-A-18 & 18 & 11.51 & 0.60 \\
SB-A-24 & 24 & 11.51 & 0.60 \\
SB-B-0 & 0 & 14.46 & 0.54 \\
SB-B-3 & 3 & 14.97 & 0.47 \\
SB-B-6 & 6 & 15.12 & 0.45 \\
SB-B-18 & 18 & 15.18 & 0.43 \\
SB-B-24 & 24 & 15.18 & 0.43 \\
SB-C-0 & 0 & 10.73 & 1.23 \\
SB-C-3 & 3 & 11.10 & 1.06 \\
SB-C-6 & 6 & 11.22 & 1.01 \\
SB-C-18 & 18 & 11.27 & 0.98 \\
SB-C-24 & 24 & 11.27 & 0.98 \\
SB-D-0 & 0 & 11.81 & 0.76 \\
SB-D-3 & 3 & 12.22 & 0.65 \\
SB-D-6 & 6 & 12.35 & 0.62 \\
SB-D-18 & 18 & 12.40 & 0.61 \\
SB-D-24 & 24 & 12.40 & 0.61 \\
\hline
\end{tabular}

(b)

\begin{tabular}{lccc}
\hline Specimen & Exposure duration (months) & $\left(B_{t}^{\text {Env. }}\right)_{p}$ & $\left(G_{f_{t}^{\text {Env. }}}^{\text {En }} p_{p}\right.$ \\
\hline SB-E-0 & 0 & 14.40 & 0.46 \\
SB-E-3 & 3 & 13.26 & 0.56 \\
SB-E-6 & 6 & 12.72 & 0.61 \\
SB-E-18 & 18 & 12.26 & 0.67 \\
SB-E-24 & 24 & 12.25 & 0.67 \\
SB-F-0 & 0 & 17.44 & 0.59 \\
SB-F-3 & 3 & 16.06 & 0.72 \\
SB-F-6 & 6 & 15.41 & 0.78 \\
SB-F-18 & 18 & 14.85 & 0.86 \\
SB-F-24 & 24 & 14.83 & 0.86 \\
\hline
\end{tabular}

and $G_{f_{t}}^{\text {Env. }}$ and it can be determined for any specific period of exposure duration just by knowing the values of $B_{0}$ and $G_{f_{0}}$ for nonimmersion case. For simplicity, $B_{0}$ and $G_{f_{0}}$ can be obtained from the original Dai model. The new calculated values of the parameters for all the specimens considering the moisture effects are shown in Table 3.

Thus, the two-parameter bond-slip relationship given in (4) can be rewritten incorporating the effect of moisture exposure duration as

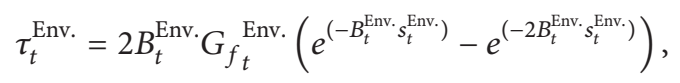

where $t$ is the duration in months.

Using (11), the bond-slip models for all the systems were prepared for different exposure durations as shown in Figure 12. 

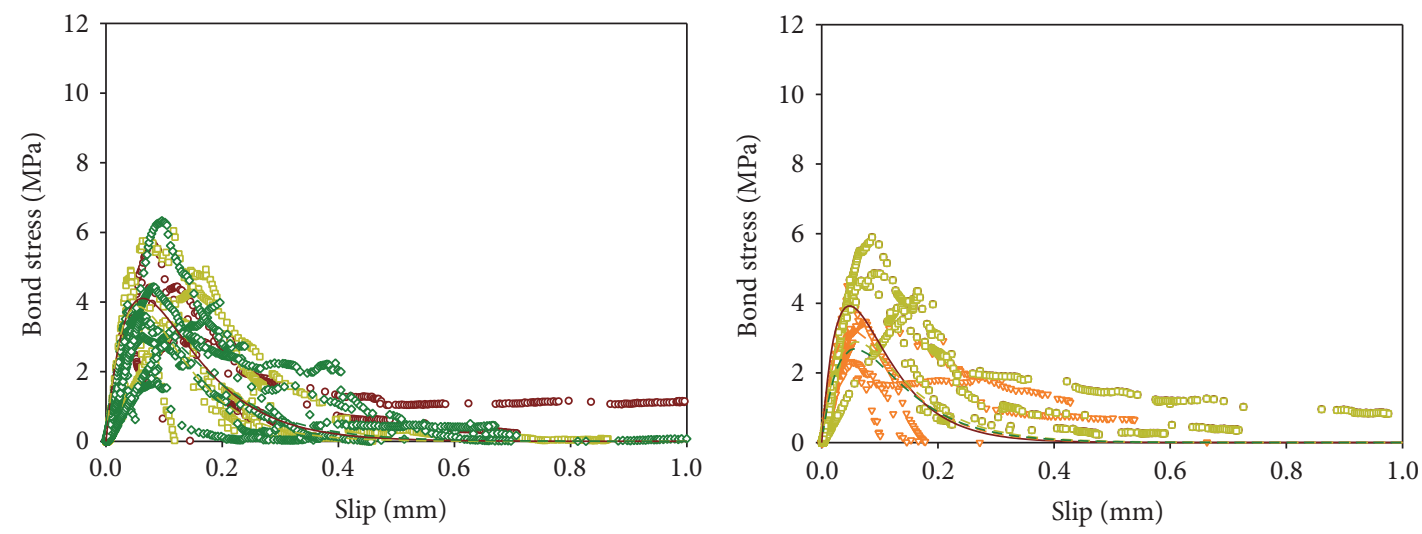

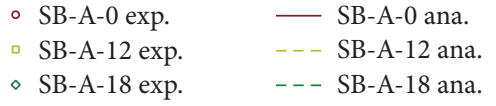

(a)

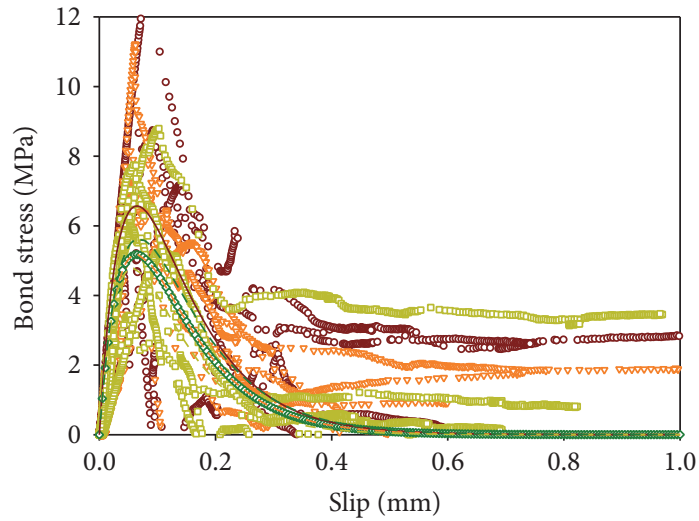

- SB-C-0 exp.

$\checkmark$ SB-C-6 exp.

- SB-C-12 exp.

॰ SB-C-18 exp.

(c)

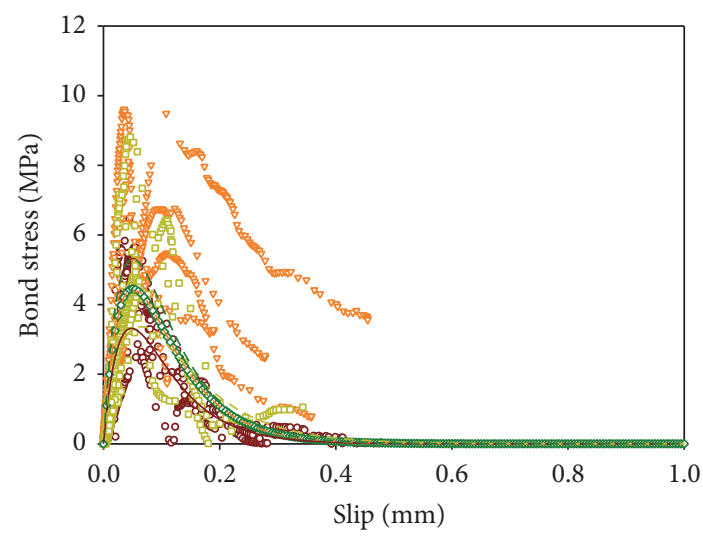

- SB-E-0 exp.

$\checkmark$ SB-E-6 exp.

- SB-E-12 exp.

$\diamond$ SB-E-18 exp.

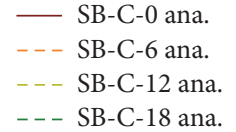

- - - SB-C-18 ana.

$$
\begin{aligned}
& \text { _ SB-E-0 ana. } \\
& --- \text { SB-E-6 ana. } \\
& --- \text { SB-E-12 ana. } \\
& \text { - - SB-E-18 ana. }
\end{aligned}
$$

(e)
- SB-B-0 exp. - - SB-B-6 ana.

$\checkmark$ SB-B-6 exp. - - SB-B-12 ana.

- SB-B-12 exp. - - SB-B-18 ana.

- SB-B-0 ana.

(b)

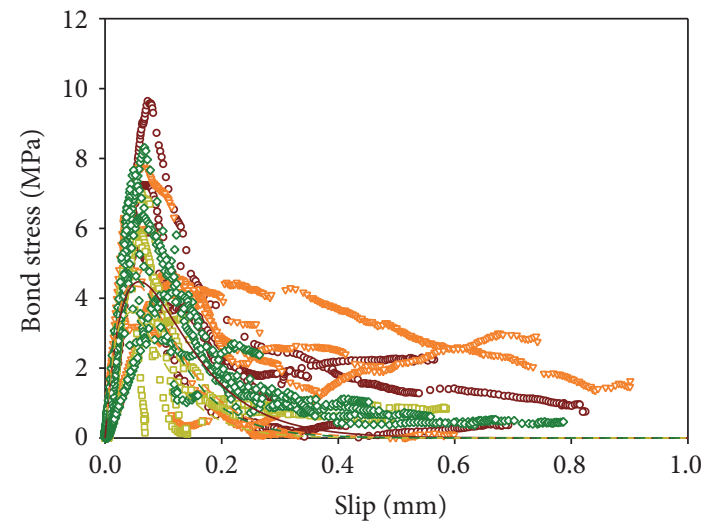
- SB-D-0 exp.
$\checkmark$ SB-D-6 exp.
- SB-D-0 ana
SB-D-12 exp.
$\diamond$ SB-D-18 exp.
-.. SB-D-12 ana.
- - - SB-D-18 ana.

(d)

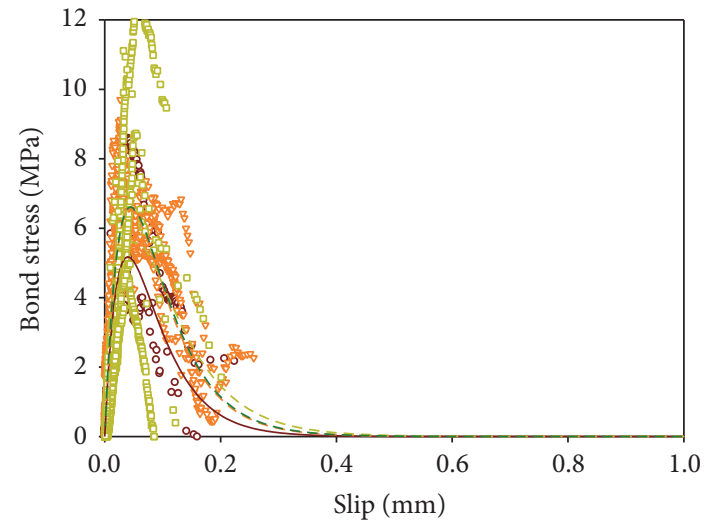
- SB-F-0 exp.
- - SB-F-6 ana.
$\checkmark$ SB-F-6 exp.
- - - SB-F-12 ana.
- SB-F-12 exp.
- - SB-F-18 ana.

- SB-F-0 ana.

(f)

FIGURE 9: Comparison of predicted bond-slip models with the experimental data. 


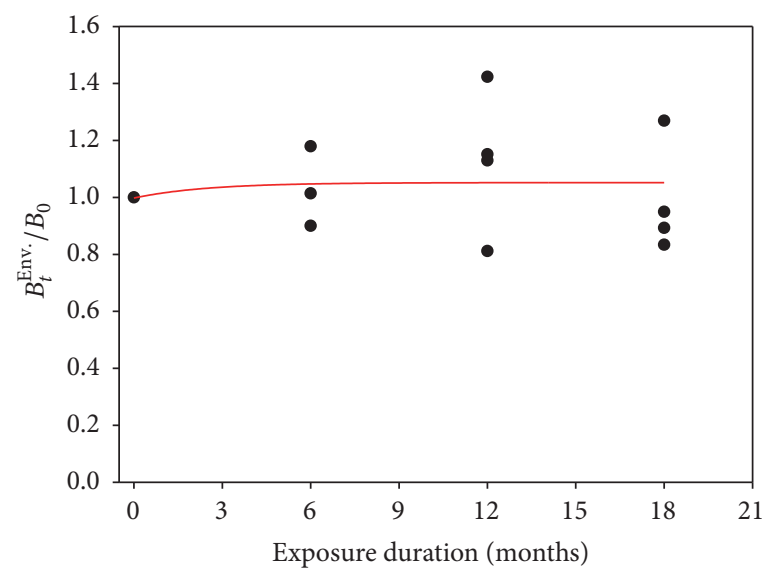

(a)

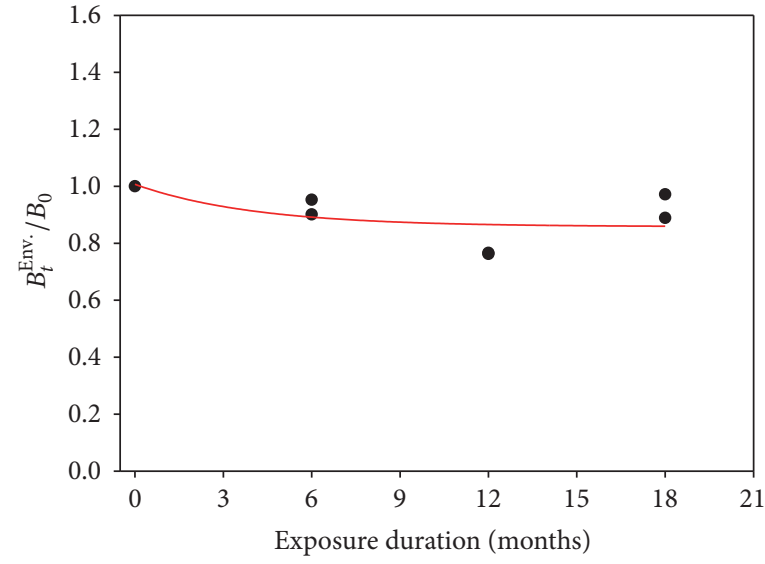

(b)

FIGURE 10: (a) Effect of exposure duration on the normalized $B$ for wet-layup FRP system. $B_{t}^{\text {Env. }}=B_{0}\left(1.05-0.05 e^{-0.40 t}\right)$. (b) Effect of exposure duration on the normalized $B$ for prefabricated FRP system. $B_{t}^{\text {Env. }}=B_{0}\left(0.85+0.15 e^{-0.25 t}\right)$.

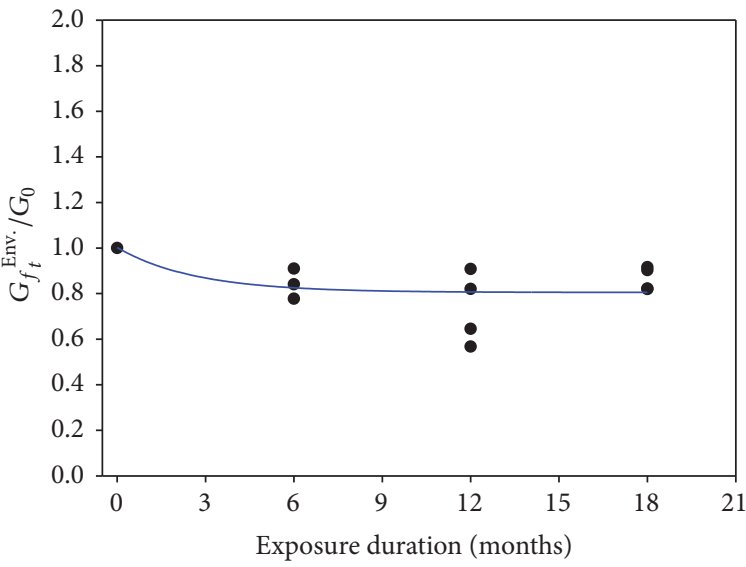

(a)

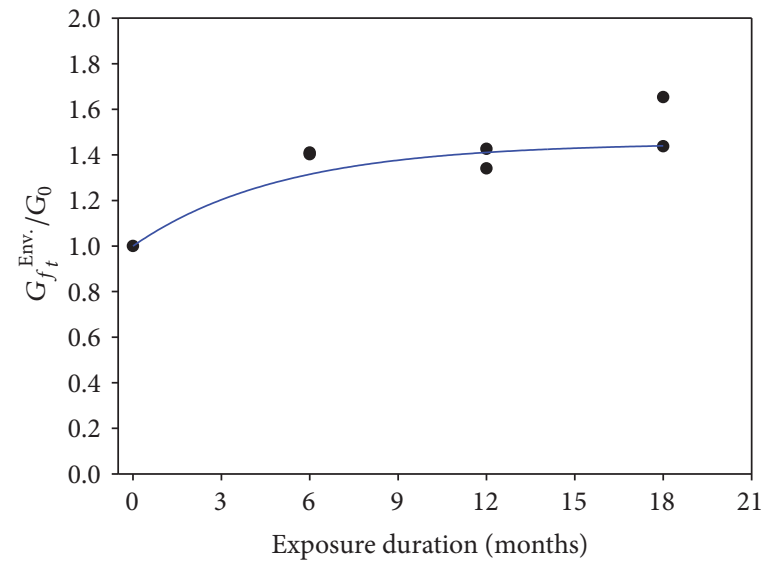

(b)

FIGURE 11: (a) Effect of exposure duration on the normalized $G_{f}$ for wet-layup FRP system. $G_{f_{t}}{ }_{\text {Env. }} / G_{f}=0.8+0.2 e^{(-0.35 t)}$. (b) Effect of exposure duration on the normalized $G_{f}$ for prefabricated FRP system. $G_{f_{t}}^{\text {Env. }} / G_{f}=1.45-0.45 e^{(-0.20 t)}$.

4.2.2. Verification of the Model. As for the verification of the proposed model for the moisture conditions, the ultimate pull-out loads from the experiment were compared with that of the predicted load. The expression for ultimate predicted load for the case of moisture exposure condition is given by

$$
P_{t}^{\text {Env. }}=b_{f} \sqrt{2 E_{f} t_{f} G_{f_{t}^{\text {Env. }}}}
$$

In the above equation, calculated fracture energies given in Table 3 were used for the exposed cases to determine the ultimate pull-out loads. Figure 13 shows good agreement of the predicted and experimental ultimate loads at $0,6,12$, and 18 months for all the 6 FRP systems investigated in this paper. The average ratio of the predicted to the experimental ultimate load was around 0.99 with an IAE of $12.84 \%$.

\section{Conclusions}

The effects of moisture conditions on the 6 different FRPconcrete bonded systems were investigated for the maximum period of 18 months. Based on the experimental results, Dai's approach of determining the nonlinear bond-slip model was modified to propose the new bond-slip models incorporating the moisture effects at the normal temperature. Some of the main points are briefly summarized below:

(1) The effect of moisture on the FRP systems can be categorized into two different cases based on the observation of average interfacial fracture energies and bond strength after exposure. In general, wetlayup FRP systems showed reduction in the interfacial fracture energy and the ultimate bond strength after exposure, whereas the prefabricated FRP systems 

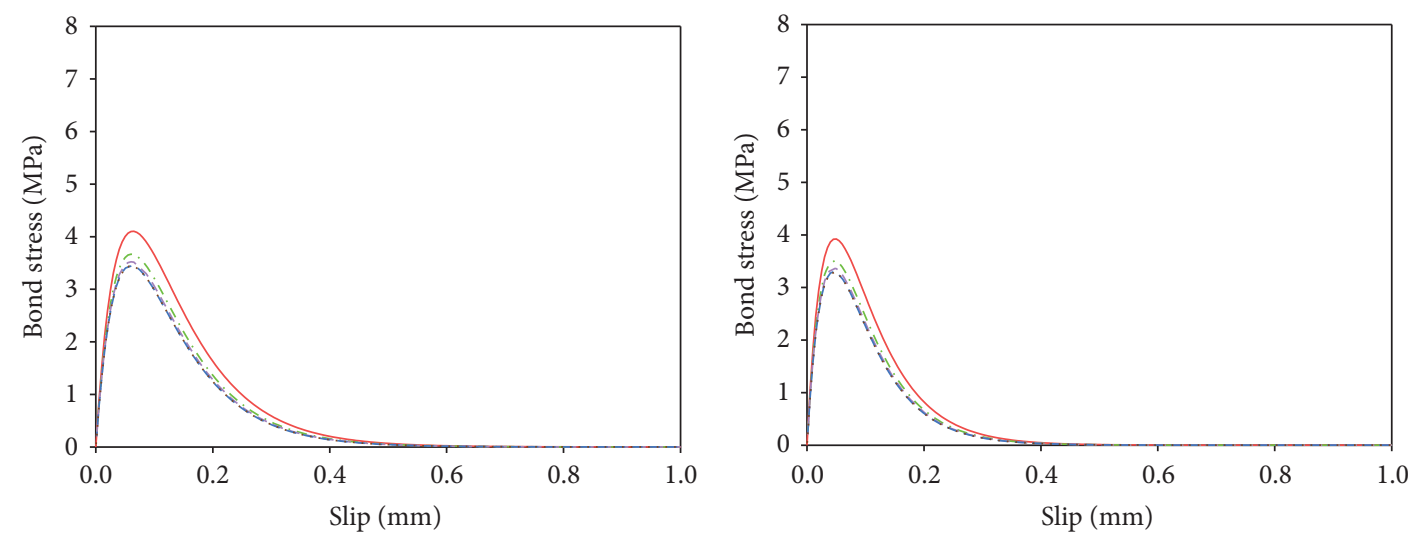

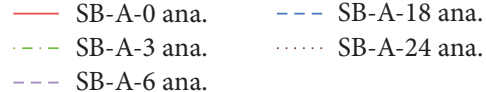

(a)

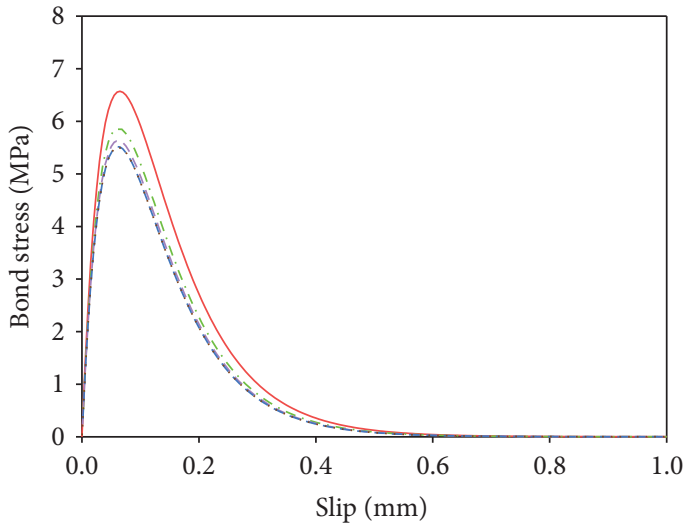

- SB-C-0 ana

- - SB-C-6 ana.

- - SB-C-12 ana

(c)

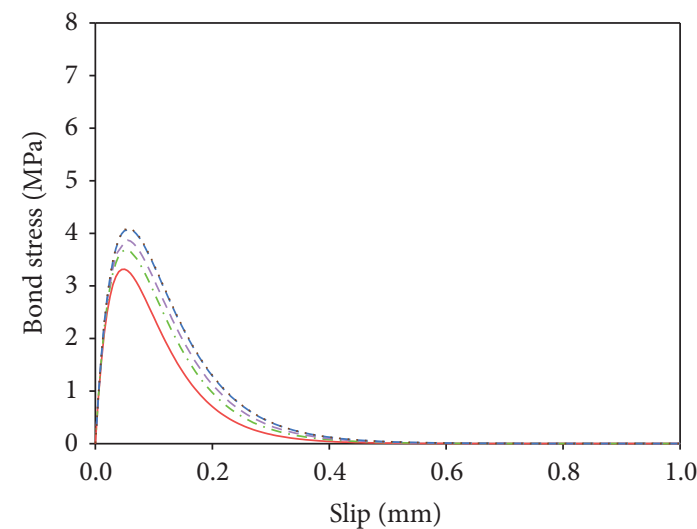

- - SB-C-18 ana

.... SB-C-24 ana.

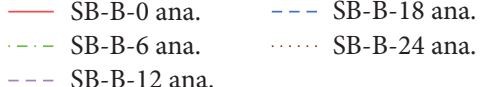

(b)

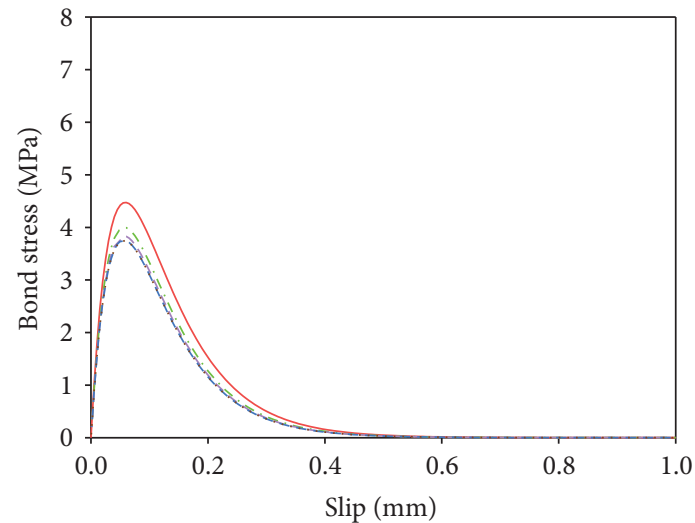

-. SB-D-6 ana.

- - - SB-D-18 ana.

- - SB-D-12 ana.

(d)

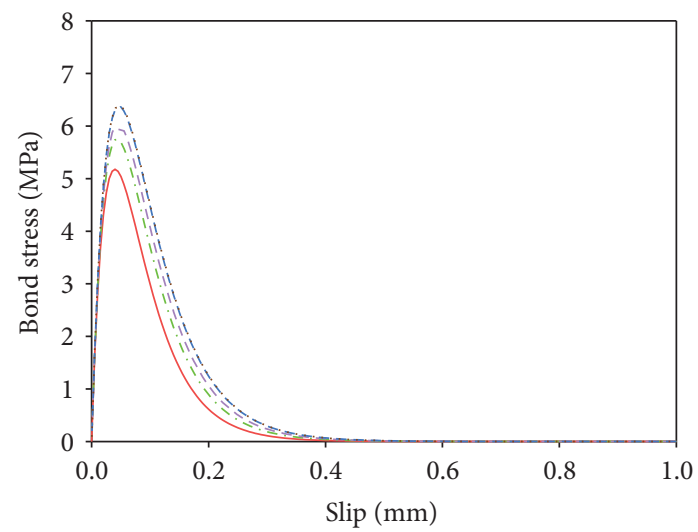

$\begin{array}{ll}\text { - SB-F-0 ana. } & --- \text { SB-F-18 ana. } \\ -\ldots & \text { SB-F-6 ana. }\end{array}$

(f)

(e)

FIGURE 12: Modified bond-slip models incorporating moisture effect. 


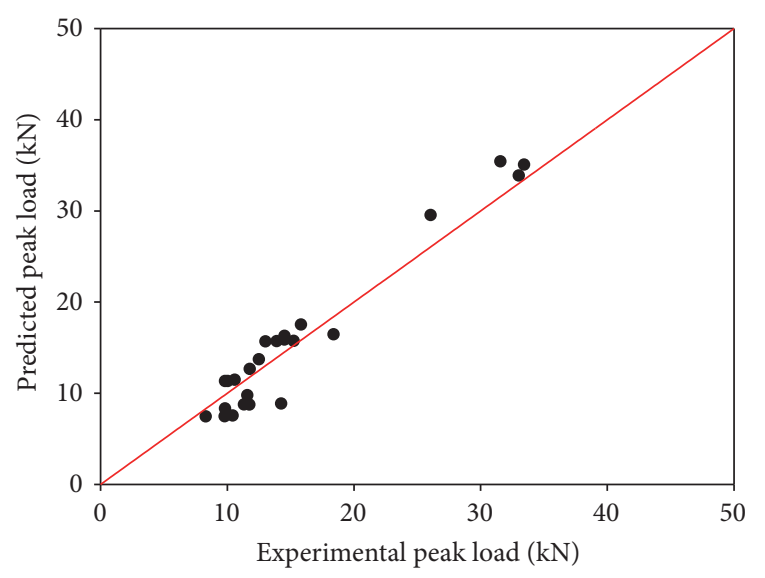

FIGURE 13: Comparison between predicted and experimental ultimate pull-out loads at $0,6,12$, and 18 months taking all the 6 FRP systems.

showed improvement. Separate bond-slip relationships have been proposed to mark such contrasting behavior.

(2) The effect of exposure duration was related to the two parameters: interfacial fracture energy $\left(G_{f}\right)$ and ductility index $(B)$ separately for the two systems. In both of the cases, the effect of moisture seems to primarily affect the bond properties until the period of the first 6 months, after which further exposure does not affect much.

(3) Bond-slip models are determined with modified fracture energy $G_{f_{t}}^{\text {Env. }}$ and ductility index $B_{t}^{\text {Env. }}$ to incorporate the effect of moisture condition and duration of exposure.

(4) The predicted ultimate loads were compared with the experimental loads at different exposure durations for all the 6 FRP systems. The results show fair agreement between the predicted and experimental values.

\section{Competing Interests}

The authors declare that they have no competing interests.

\section{Acknowledgments}

The authors acknowledge the support of Nippon Steel and Sumikin Materials Co., Ltd.; Mitsubishi Plastics Infratec Co., Ltd.; FYFE Japan Co., Ltd.; Simpson Strong-Tie Asia Ltd.; and Sika Ltd. for providing necessary materials to conduct this research work. The financial support from the Research Fund of Ministry of Transport Construction Technology (2014318494020) and Grant-in-Aid for Scientific Research (A) of Japan Society of Promotion of Science (no. 26249064) and NEXCO Group Companies' Support Fund to Disaster Prevention Measures on Expressways is greatly appreciated. The authors also highly appreciate the support of
Mr. Tsutomu Kimura for his technical assistance during the experiments.

\section{References}

[1] J. Shrestha, T. Ueda, and D. Zhang, "Durability of FRP concrete bonds and its constituent properties under the influence of moisture conditions," Journal of Materials in Civil Engineering, vol. 27, no. 2, Article ID A4014009, 2015.

[2] S. Choi, A. L. Gartner, N. V. Etten, H. R. Hamilton, and E. P. Douglas, "Durability of concrete beams externally reinforced with CFRP composites exposed to various environments," Journal of Composites for Construction, vol. 16, no. 1, pp. 10-20, 2012.

[3] K. Benzarti, S. Chataigner, M. Quiertant, C. Marty, and C. Aubagnac, "Accelerated ageing behaviour of the adhesive bond between concrete specimens and CFRP overlays," Construction and Building Materials, vol. 25, no. 2, pp. 523-538, 2011.

[4] C. Tuakta and O. Büyüköztürk, "Deterioration of FRP/concrete bond system under variable moisture conditions quantified by fracture mechanics," Composites Part B: Engineering, vol. 42, no. 2, pp. 145-154, 2011.

[5] J. G. Dai, H. Yokota, M. Iwanami, and E. Kato, "Experimental investigation of the influence of moisture on the bond behavior of FRP to concrete interfaces," Journal of Composites for Construction, vol. 14, no. 6, pp. 834-844, 2010.

[6] J. Shrestha, T. Ueda, D. Zhang, A. Kitami, and A. Komori, "Investigation on moisture behabior for different FRP-concrete bonded systems," in Proceedings of the JCI Annual Convention, pp. 1135-1140, Chiba, Japan, 2015.

[7] T. Ueda and J. G. Dai, "Interface bond between FRP sheets and concrete substrates: properties, numerical modeling and roles in member behaviour," Progress in Structural Engineering and Materials, vol. 7, no. 1, pp. 27-43, 2005.

[8] J. Dai, T. Ueda, and Y. Sato, "Development of the nonlinear bond stress-slip model of fiber reinforced plastics sheet-concrete interfaces with a simple method," Journal of Composites for Construction, vol. 9, no. 1, 2005.

[9] J. G. Dai, W. Y. Gao, and J. G. Teng, "Bond-slip model for FRP laminates externally bonded to concrete at elevated temperature," Journal of Composites for Construction, vol. 17, no. 2, 2013.

[10] Y. Yun, Durability of FRP-concrete interface [Ph.D. thesis], City University of Hong Kong, 2011.

[11] Z. Ouyang and B. Wan, "Experimental and numerical study of moisture effects on the bond fracture energy of FRP/concrete joints," Journal of Reinforced Plastics and Composites, vol. 27, no. 2, pp. 205-223, 2008.

[12] Z. Ouyang and B. Wan, "Nonlinear deterioration model for bond interfacial fracture energy of FRP-concrete joints in moist environments," Journal of Composites for Construction, vol. 13, no. 1, pp. 53-63, 2009.

[13] M. A. G. Silva, H. C. Biscaia, and R. Marreiros, "Bond-slip on CFRP/GFRP-to-concrete joints subjected to moisture, salt fog and temperature cycles," Composites Part B: Engineering, vol. 55, pp. 374-385, 2013.

[14] J. Shrestha, D. Zhang, and T. Ueda, "Durability performances of carbon fiber-reinforced polymer and concrete-bonded systems under moisture conditions," Journal of Composites for Construction, vol. 20, no. 5, Article ID 04016023, 2016. 
[15] Z. C. Girgin, N. Arioglu, and E. Arioglu, "Evaluation of strength criteria for very-high-strength concretes under triaxial compression," ACI Structural Journal, vol. 104, no. 3, pp. 278284, 2007.

[16] Y.-F. Wu and C. Jiang, "Quantification of bond-slip relationship for externally bonded FRP-to-concrete joints," Journal of Composites for Construction, vol. 17, no. 5, pp. 673-686, 2013.

[17] T.-C. Nguyen, Y. Bai, X.-L. Zhao, and R. Al-Mahaidi, "Durability of steel/CFRP double strap joints exposed to sea water, cyclic temperature and humidity," Composite Structures, vol. 94, no. 5, pp. 1834-1845, 2012.

[18] M. S. Sciolti, M. Frigione, and M. A. Aiello, "Wet lay-up manufactured FRPs for concrete and masonry repair: influence of water on the properties of composites and on their epoxy components," Journal of Composites for Construction, vol. 14, no. 6, pp. 823-833, 2010. 

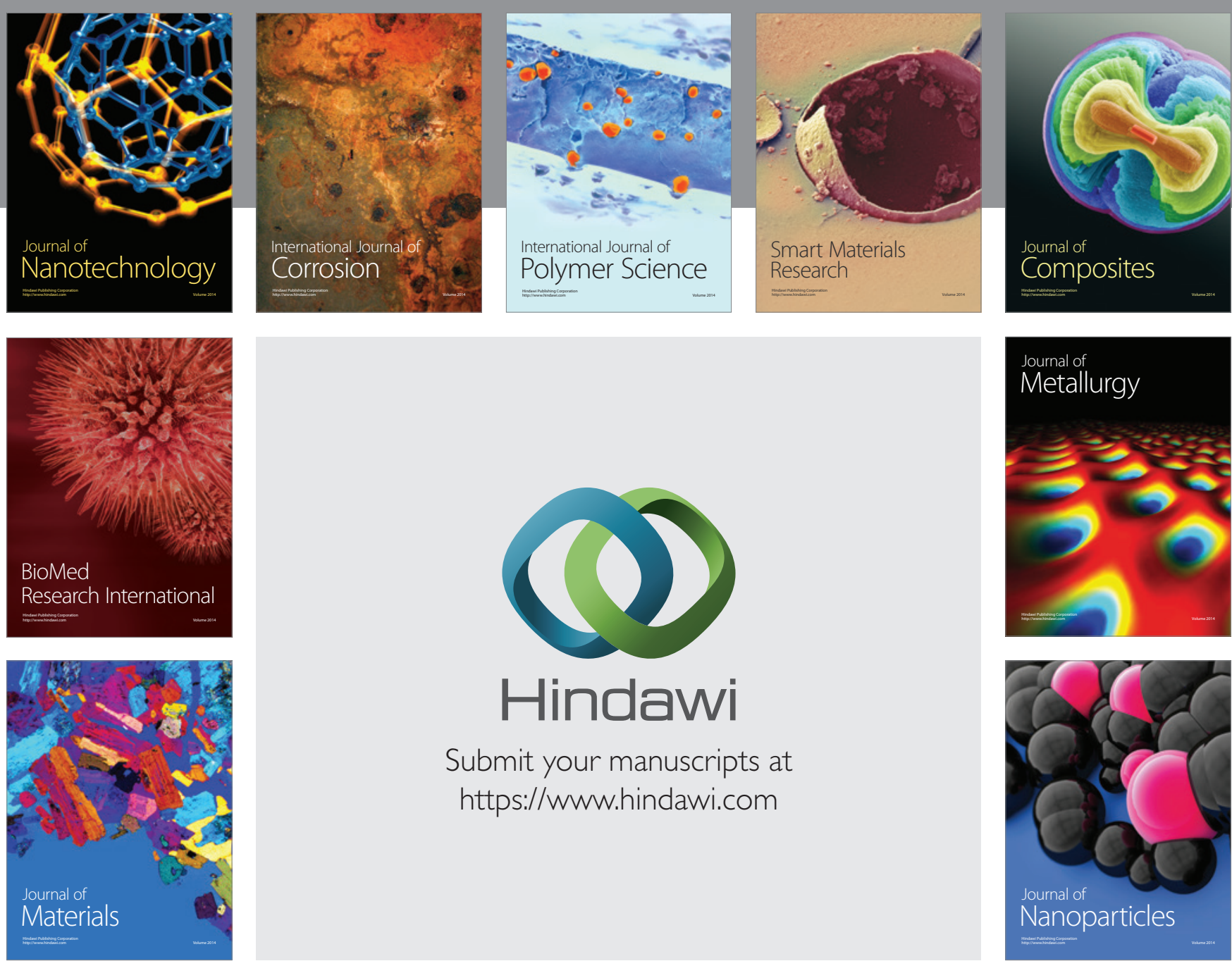

\section{Hindawi}

Submit your manuscripts at

https://www.hindawi.com

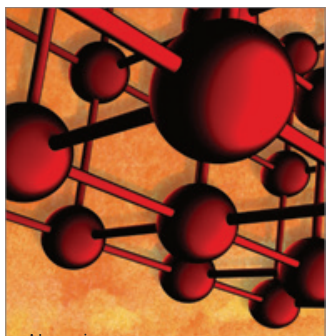

Materials Science and Engineering
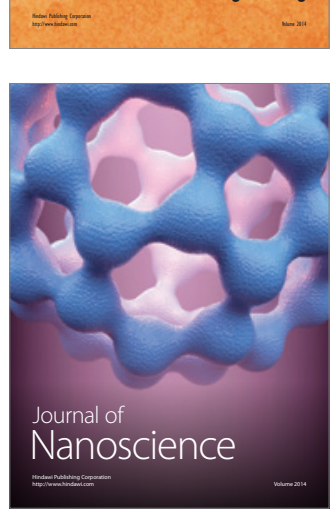
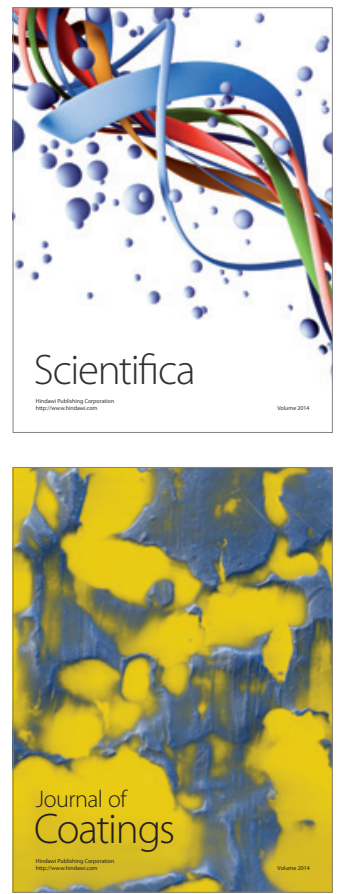
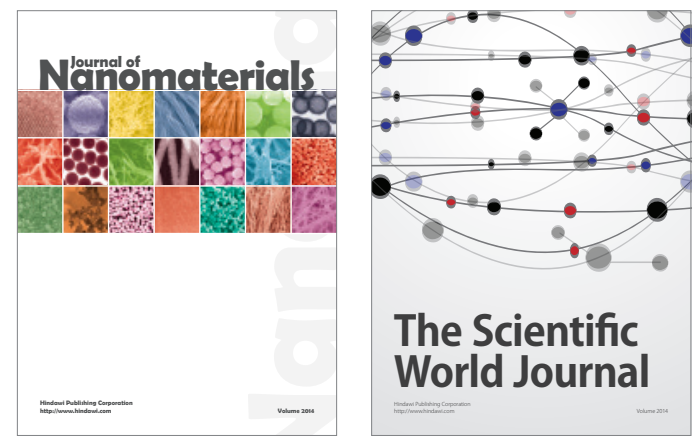

The Scientific World Journal
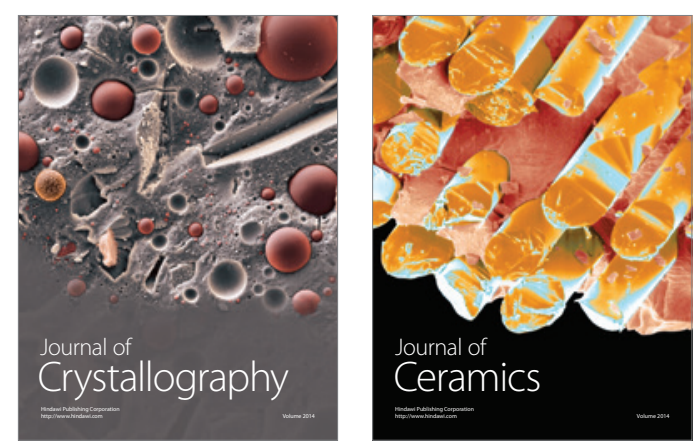
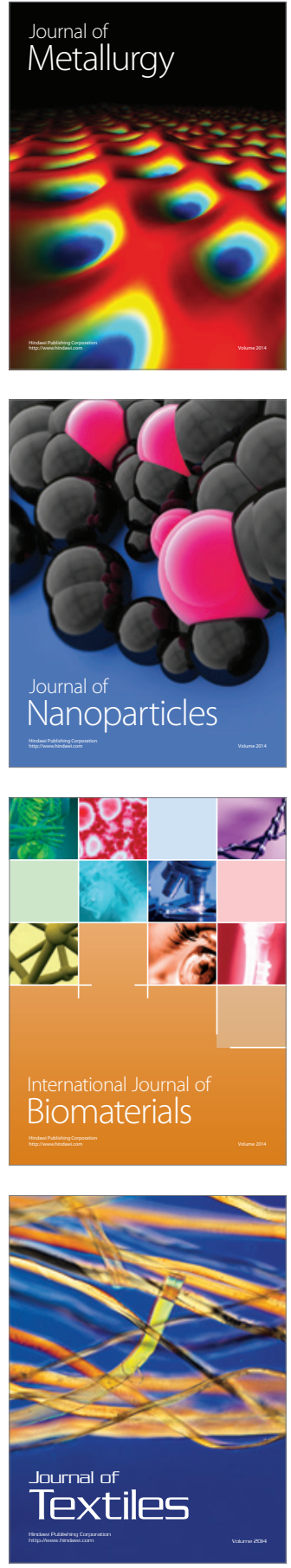